\section{As políticas públicas de comunicação na Europa: uma análise a partir da perspectiva dos macroespaços regionais}

Tradução: Profa. Dra. Neusa Demartini Gomes

Marcial Murciano

Sociedade Catalã de Comunicação

\section{Introdução}

O ESTUDO DOSSISTEM AS decomunicação, a partir daperspectivadesuaaçãointernacional, vem sendo significativamente modificado, já que está afeto aos acontecimentos ocorridos durante a última década e, portanto, é necessária uma nova abordagem dos temas tradicionais da informação, da comunicação ou das novas tecnologias nos sistemas portadores de mensagens.

Um dos aspectos centrais que caracterizam este deslocamento de perspectiva reside na intensificação da atual fase de mundial ização regional izada em que nos encontramos, como conseqüência da dinâmica econômica de mundialização em curso, dinâmica esta que o pensamento anglo-saxão vem denominando atualmente de globalização, atendendo sobretudo aosaspectostecnológicosqueestão transformando nossa perspectiva deespaço e de tempo.

Como se sabe, o pensamento crítico latinoamericano já havia introduzido nos anos oitenta o conceito de transnacional ização para estudar estes mesmos fenômenos.

Este texto não pretende se fixar na complexa problemática teórica que a mundialização introduziu.

O que interessa é sublinhar que o tema das 
políticas de comunicação se insere no marco que define a regionalização do sistema mundial.

N essecontexto serão anal isadas as principais características das políticas públicas de comunicação no espaço europeu.

Mundialização regionalizada e macroespaço europeu

Umadas características quesesobressaem da mencionada dinâmica de mundialização éa configuração de uma nova articulação dos espaços comunicativos.

Diante dos enfoques tradicionais de quase vinte anos, nos quais analisava-se a oposição das forças nacionais frente à emergência de uma crescente atividade exterior transnacional, a característica da atual fase é identificar no cenário planetário ao menos quatro espaços de atividade comunicativa, cada vez mais diferenciados. Estes espaços são, numa ordem demaior amenor dimensão: em primeiro lugar, o espaço global, que favorece a nova tecnologia e no qual se incrementaumadifusão cadavez maisampla demensagenssincrônicas; emsegundolugar, os espaços supranacionais, ou espaços regionais, característicos da atual fase de regionalização; em terceiro lugar, o espaço tradicional do Estado nação; e, por último, e cada vez com uma maior identidadeprópria, os espaços locais, diferenciados por suas características de comunidade específica (língua, história, religião, costumes, território, etc.).

É importante introduzir o tema das políticas de comunicação na União Européia no contexto desta nova dinâmica de espaços comunicativos.

O espaço regional em construção mais desenvolvidoé, desde1992, aUniãoEuropéia. A integração, não só econômica, mastambém política e cultural, vem configurando todo umamplo mercado quena atualidadesupera os 350 milhões depessoas eno qual seproduz aproximadamente uma quarta parte do PIB mundial eum pouco mais do queaterçaparte do comércio mundial.

Esta integração vem originando uma importante dinâmica de mudanças de todo o tipo: políticas, jurídicas, comerciais, além de ser também a motora de uma série de transformações que se observam na esfera comunicativo-cultural, por outra parte, muito afetadapeladinâmicadeinovaçãotecnológica ocorrida na última década.

Em duas décadas aEuropa seconverteu num dosmodernos espaçosgeoeconômicosquese desenvolveram por todo o planeta. $\mathrm{Na}$ atualidade, este processo de integração está composto por quinzeestadosmembros- após a recente incorporação da Áustria, Suécia e Finlândia- eháumalista demais dozepaíses da Europa Central eOriental quesolicitaram ingresso, dos quais a metade poderia aderir depois da unificação da moeda européia, prevista para o final do século. Estas integrações dariam uma dimensão demográfica à união acima dos 400 milhões de habitantes eum espaço geográfico ampliado, queiria do A tlântico atéas fronteiras daatual Rússia.

A maneiracomo seavançou, no caso daUnião Européia, não constitui um exemplo isolado na construção dos macroespaços regionais, mas sim o model o mais acabado desta nova tendência. Dentro dela podemos considerar também a integração econômica que está se produzindo no Atlântico Norte, com a ratificação de Tratado de Livre Comércio, liderado pel os Estados Unidos que integram as economias deste país, Canadá e México.

No Pacífico estão iniciando as bases, já a muito tempo, para uma associação similar, prevista para o início do próximo século, apesar de parecer difícil ao Japão liderar um espaço em queseacham também envolvidas a China e a Índia, que por suas dimensões e 
potência cultural, são verdadeiros macroespaços em si mesmas.

A outra grande experiência regional em marchaestáconstituídapel osul do continente americano, onde se acelera a integração dos paísesmeridionaissobaassinaturadoTratado doM ercosul, liderado peloBrasil eA rgentina, no qual participam também Uruguai e Paraguai.

Podemosacrescentar mais duas regiõesaesta nova ordem mundial.

Por um lado a ex- União Soviética, a atual Rússia, partedecujos problemas residem em suatransformação num espaço regional, com moeda, exército e economia unificados.

Por outro, o mundoárabequeiniciou háduas décadas diversos processos de unificação regional sem grandes êxitos até o momento, masquecontacomtodososfatoresquepodem fomentar sua união: mesmo idioma, mesma tradição histórica e cultural, necessidade econômica e vontade política.

Esta nova forma de agrupamento de economias e espaços nacionais, tanto se realiza como avança, no meio da dinâmica de integração da economia mundial e exige uma redefinição dos sistemas de comunicação e de seus espaços de atuação, que agora se encontram conectados por uma nova dinâmica de articulação que tem uma lógica de ação global, e qual Ihe infere a atividade econômicamundializada; os principaisatores econômicosquedefinem estes novos espaços são as modernas empresas transnacionais.

Os meios de comunicação, no meio de todos estes macroespaços, constituem um dos elementos centrais; por exemplo, favorecem a criação e a difusão da moderna cultura audiovisual, redefinem as novasidentidades coletivas, contribuem para a criação de uma cultura política comum, etc.

A esferadocomunicativo portanto, oelemento deenlaceentreosnovos espaços regionaisea dinâmica global do sistema. A esfera comunicativa constitui o nexo simbólico que permite a articulação dos espaços mencionados: o local, o nacional, o regional e o mundial.

Os grandes organismos de atuação nas políticas públicas de comunicação européias

Aocontráriodeumaidéiabastantedifundida, no espaço europeu e no âmbito das políticas públicas de comunicação coexistem na atualidade diversos organismos supranacionais de atuação, cujos principais são:

- Em primeiro lugar, a União Européia, que inclui os 15 países quefirmaram o tratado da União, em 1992, equeseencontram comprometidos no processo de integração européia. Fundamentalmente é a Comissão européia quem toma as iniciativas em matéria de políticasdecomunicação, apesar quetambém o Parlamento da União eo Consel ho também o fazem, eque são órgãos com competências e poder diferentes.

-Em segundo lugar o grande ator é constituído pelo Conselho da Europa, instituição fundada em fins dos anos cinqüenta. É o organismo europeu mais representativo - ao qual pertencem mais de trinta países e integra a quase totalidade dos países da Europa Oriental -, mas com um menor peso epoder na definição das políticas européias.

- O terceiro ator é a União Européia da Radiodifusão (UER), fundada em 1950, na qual se encontram integrados a totalidade dosorganismos públicoseuropeus derádioe televisão.

- Por último, a Organização Européia de Satélites de Comunicação (EUTELSAT), fundada em 1977, que agrupa os Correios e Telecomunicações públicos europeus e atua 
como um ramo regional da organização mundial INTELSAT. Em geral, na Europa, os organismos de Correios eTelecomunicações são as instituições encarregadas da transmissão e devem negociar com eles a distribuição de emissões.

São pois estes quatro atores os que intervêm significativamente e em grau diverso, na configuração depolíticas decomunicação nos quatro âmbitos principais que vem a seguir:

1 A política organizadora de emissões de televisão.

2 A políticadepromoção deumaindústria audiovisual.

3 A política de telecomunicações (regulamentação, desenvolvimento denovasredes, esquemas das rotas da informação, etc.).

4 A políticaindustrial demateriais paraa comunicação (no setor eletrônico, informático, de equipamentos, etc.).

\section{A atuação da União Européia em políticas de comunicação}

A téa assinatura do recentetratado da União, em 1992, as competências de atuação da Comunidade Européia em matéria de comunicação estavam limitadas aos aspectos econômicos e industriais (bens e serviços). N este sentido, a comunicação - e mais concretamente o cine e a televisão - somente puderam ser tratados como atividades econômicas. O tratado de 1992, depois deum intenso e controvertido debate, atribuiu à União competências culturais que até o momento, no espaço europeu, somente o Consel ho da Europa desempenhava.

Detodasas instituições daUnião, aComissão (o executivo europeu) éa que vem tendo um papel maisativo. Asiniciativasdesenvolvidas pela Comissão se encontram repartidas em três departamentos (direções) encarregados da elaboração de informes e estudos específicos em matéria de comunicação:

- A D ireção G eral III, encarregada do M ercado interno e os Assuntos Industriais.

- A D ireção Geral X, dedicada à informação, à Comunicação eà Cultura.

- A Direção Geral XIII, dedicada às Telecomunicações, às Indústrias da Informação eà Inovação.

Desde princípios dos anos 80, fundamentalmente estes três departamentos se encarregaram de abordar os diferentes aspectos das políticas de comunicação européias: a dimensão jurídica, a dimensão comunicativa e a cultural, e a dimensão tecnológica e industrial.

A primeira atuação significativa da União no campo da televisão se remonta a doze anos. Em 1984, a Comi ssão apresenta um primeiro informe: 0 Livro V erde para o estabelecimento de um mercado comum da televisão na Europa, conhecido posteriormente como "Direcionamento sobre a televisão sem fronteiras". O objetivo do informeera estudar a situação do audiovisual entre os países membros e a necessidade de:

1) desenvolver uma política coerente para a harmonização do setor nos diferentes países - sobretudo no que se refere à publicidade, à proteção da juventude, ao direito deresposta e aos direitos de autor;

2) propor uma política comunitária comum capaz de superar as dificuldades nacionais existentes em cada país e responder conjuntamente às grandes metas econômicas e culturais envolvidas no setor audiovisual.

Dois anos mais tarde, em 1986, os conteúdos do informesetransformaram numa proposta de direcionamento comunitário (lei para os estados membros) na qual se definiram os aspectos centrais da União no campo da 
política audiovisual.

O direcionamento propunha, em primeiro lugar, o planejamento de uma política tecnológica-industrial para os equipamentos audiovisuais e sugeria a adoção de normas técnicascomuns, emespecial na promoção de uma norma para o desenvolvimento da televisão de alta definição e sua estandardização em nível mundial.

Em segundo lugar, estabel ecia um programa de política econômica industrial com o propósito de gerar o espaço audiovisual europeu, por meio da liberdade para a livre retransmissão de qualquer emissão de televisão e sua livre recepção sem nenhum tipo deentraves. A téessemomento o mercado europeu do audiovisual seencontrava muito fragmentado pelas normativas nacionaiseas obras européias circulavam com bastante dificuldade entre os diferentes países (a produção européia difundida na região era de, no máximo, 8\%).

Porúltimo, o direcionamentosentava as bases para o desenvolvimento deuma indústria de programas audiovisuais europeus - transformadas depois no Programa MEDIA (M edida para impulsionar e desenvolver uma industria audiovisual européia) - capaz de responder ao objetivo político e cultural de promover adistribuição deobrasaudiovisuais européias entre a comunidade, frente às posições dominantes que ocupam os Estados Unidos eo Japão, tanto no mercado europeu quanto no mundial.

Nesta primeira fase da política européia se centram dois grandes objetivos:

1 Por um lado, na consideração dos aspectos vinculados com a dimensão tecnológica, industrial e econômica da comunicação, objetivados no setor audiovisual, campo que aglutina tanto os meios tradicionais quanto o cinema, a tel evisão eo vídeo, assim como as infra-estruturas introduzidas pela nova tecnologia (satélites, cabos enovas redes portadoras).

O interesseeuropeu sefocal izaprincipalmente em fomentar e desenvolver este grande setor econômico e industrial, por outra parte tão estratégico e sensível na nova economia mundializada dos anos oitenta. Dados de 1993, estabelecidospel o Consel ho daEuropa, avaliavamem 10bilhõesdepesetasaatividade econômica do audiovisual europeu.

Sem dúvida, o audiovisual se converteu em poucos anos num dos setores de maior projeção e importância para qualquer economia avançada. A televisão, como meio demultirrecepção, constitui o elemento básico paratodauma sériederedes decomunicação - as hertzianas, as de cabo e as de satélite, aglutinando uma atividade econômica que supera, por completo, os marcos geográficos tradicionais.

Osobjetivoseuropeusforamsendo centrados na construção de uma indústria européia competitiva frente à concorrência dos norteamericanosejaponeses. Das 130.000 horas de programasveiculados naEuropaamediados dos anos 80, somente 25.000 eram produções européias. A metade dos programas importados era norte-americana e $60 \%$ do cinema distribuídonaEuropaeratambémamericano.

Quanto ao queserefereà políticaindustrial e a uma tecnologia para o desenvolvimento da televisão dealtadefinição(TVAD), acomissão aprovou, em 1986, direcionamentos que comprometiam todosos estadosmembrosna aceitação de um estandar de alta definição denominado M A C Paquets, quefoi capaz de bloquear a adoção mundial por parte do Comitê Consultivo Internacional para as radio-comunicações (CCIR) da norma japonesa MUSE, muito mais avançada no seu processo dedesenvolvimentotecnológico. A adoção da norma japonesa havia significado, em termos de política industrial, um fracasso para os interesses europeus, já que toda a cadeia de produção audiovisual depende do tipo e norma adotados. 
2 Em segundolugar, na consideração dos aspectos associados à dimensão política e cultural da comunicação. Para a Comunidade Européia, o interesse em atuar em matéria de comunicação deve estender-se como uma vontadepolíticaexplícitapor superar o antigo marco de problemas existentes no conjunto dasnaçõeseuropéias, muito fragmentado por diferentes interesses tradicionais, políticos, culturais e lingüísticos. Por exemplo, o direcionamento sobre a televisão sem fronteiras é o primeiro instrumento político quepermitesuprimir o regimedemonopólio que durante mais de 40 anos havia estado vigente na Europa e havia estruturado a totalidade dos sistemas de radiodifusão europeus.

A intervenção em matéria de comunicação abreas expectativas para a redefinição deum grande projeto cultural europeu, que se concretiza depois de 1992, data em que se concedem as competências culturaisà União. Do ponto devista político, o projeto cultural comum para os quinze permite reforçar a coesão que induz à integração econômica, por meio daexpressãodadiversidadecultural queas diferentesculturasnacionaiseuropéias expressam. Porém, até o momento, a europeização da cultura do velho continente se identificou mais pela sua oposição às ameaças de americanização das indústrias culturais européias ou as denúncias de japonização tecnológica, que a consecução de umaespecíficaidentificação coletivaeuropéia. O estabelecimento de uma política cultural comum é uma meta maior ainda a alcançar no projeto federal europeu.

Além deumdirecionamento comentado para o estabelecimento de uma norma comum no espaço europeu na tel evisão dealta definição edo direcionamento para a harmonização do mercado da televisão, a U nião Européia vem intervindo de maneira decisiva na definição de um Programa de ajuda para a promoção da indústria de obras para o cinema e tel evisão (Programa MEDIA), através de um amplo conjunto de iniciativas que podem comple- mentar os objetivos definidos pelas políticas tecnológicas e econômicas já mencionadas.

O Programa MEDIA foi criado pelaD.G.XII queéo departamento encarregado dostemas mais espeć́ficos de comunicação e cultura - , em 1987, por proposta do Parlamento e da Comissão das Comunidades Européias.

Em princípio funcionou experimentalmente, entre 1988 e1989, emais adiante, entre 1990 e 1995, com caráter plurianual. Esta primeira fase ficou conhecida com o nome de MEDIA 92 ea segundacomo MEDIA 95. A tualmente, oProgramaseencontranumaterceirafase, na qual estãoseredefinindo osobjetivosiniciais.

O programa foi criado para atender as necessidades de ajuda para o fomento do setor da produção, da distribuição e do financiamento dos programas de cinema e televisão na Europa. O objetivo do programa era a criação de amplas redes para a colaboração em projetos europeus, fomentados por um capital financeiro dividido a $50 \%$, nos custos iniciais, que permitiram a atração de fontes financeiras complementárias.

Capitais provenientes de fundos públicos europeus, organizações profissionais, empresas privadas e "esponsors" contribuíram para criar, desta forma, um número importante deatuações européias. Em fins de 1990, os fundos comprometidos no programa MEDIA ascendiam aos 11 mil hões deECUSe haviam gerado atividades no setor audiovisual num valor superior a 300 milhões de ECUS.

\section{A Comissão estabeleceu trêsamplosobjetivos para o programa MEDIA:}

1. Unificar os mercados nacionais e criar sinergias transfronteiriças que permitam aos operadores reforçar sua posição graças às economias de escala.

2. Contribuir para a reestruturação da 
indústria audiovisual, dando prioridade às pequenas e médias empresas e abarcando todos os do campo audiovisual, já que estes são independentes.

3. Respeitar as sensibilidades e identidades nacionais e evitar a uniformidade cultural, levando em conta os interesses dos Estados menores e os idiomas menos praticados.

O Programa MEDIA está baseado na estreita colaboração comosprofissionaisda indústria audiovisual (cinema, televisão, vídeo, satélites e cabo) e sua ação se situa ao largo de toda a fasedeprodução edacadeiaindustrial gerada, semintervir no financiamento direto deobras concretas. Por norma geral, as ajudas financeiras que concede são antecipações sobre a bilheteria, reembolsáveis posteriormente. Osvaloresdevolvidosseintegram outra vez ao fundo esão reinvestidos. Na sua fase mais avançada, o programa inclui quase vinte âmbitos de atuação e financiamento divididos em seis campos principais:a formação de profissionais, a melhoria das condições de produção, a distribuição, a exploração e financiamento e 0 desenvolvimento de segundos mercados (arquivos, reposições, etc.). Os fundos orçamentados parao período 1991-1995foramde200milhões deECUS. O programaMEDIA nãovemsendo limitadoaos 15paísesmembrosquecompõem a União Européia, mas se abriu aos países da Europa Central e Oriental. Mais de duas mil sociedades e organizações, principalmente pequenas e medias empresas participaram no período 1988-1995.

Entreas principaisiniciativas impulsionadas pelo Programa MEDIA se encontram: a O ficina Européia de Distribuição de Filmes (EFD O), com base em Hamburgo; o Espaço de Vídeo Europeu (EVE), coordenado pela Midiateca da Bélgi ca epelo Instituto Irlandês do Filme; o Fundo Europeu para o desenvolvimento do multilingüismo A udiovisual (BA BEL), estabelecido na Suíça. A A ssociação Européia para o Mercado Audiovisual Independente (EURO-AIM); o Clube de
Investimentos M edia (M IC), uma colaboração do INA francês e as grandes empresas européias; a A ssociação Européia de D esenhos A nimados (CARTOON); a M edia Bussines School (M BS), estabelecida em Madri com a ajuda do Instituto Espanhol de Cinema edas Artes Audiovisuais, o programa SCRIPT, de ajuda à elaboração de roteiros, etc.

Depois da assinatura do tratado da União, a Comissão Européia tem orientado sua preocupação política de forma a harmonizar as situações monopolísticas de domínio existentes no setor dos meios europeus. $O$ Informe sobre o Pluralismo e concentração dos meios no mercado interno (livro verde, de dezembro de 1992) constitui um rascunho de trabalho em curso muito controvertido, poisintroduz a necessidadedecriar em nível europeu uma instituição independente encarregada de harmonizar as políticas nacionais em favor do pluralismo dos meios, desfavorecido pela tendência internacional para a convergência e a concentração multimídia.

A última preocupação em política de comunicaçãonaUniãoEuropéiaéconstituída pela reflexão em volta da sociedade da informação e a liberalização do setor das telecomunicações, estruturado na Europa majoritariamente em monopólios públicos. O recente Informe Bangemann, sobre a E uropa e a sociedade global da informação, apresentado em 1994, por um grupo depolíticose empresárioseuropeus, instaaU nião Européia a estabel ecer um regulamento quefavoreça a aparição de novos setores dinamizadores da economia, em toda a Europa, como também do estabelecimento de um mercado competitivo paraosserviços deinformação, nalinha da ortodoxia liberal internacionalizada.

\section{As políticas do Conselho da Europa}

O Conselho da Europa elaborou diversas medidas (paralelamente e em ocasiões confluentescomasintervençõesdaUnião em 
matéria de políticas de comunicação), no campo do audiovisual e dos meios de comunicação por meio deum ComitêDiretor para os Meios de Comunicação de Massas (CDMM). O Conselho da Europa é um organismo geograficamente com um campo deação mais amplo quea União, equeatinge mais ou menos trinta países europeus, mas tem um menor peso coercitivo na aplicação e seguimento daspolíticas decomunicação que desenvolve. $O$ quadro regulamentar que elaborasetransformanumaação denominada conven ção à qual os países membros aderem voluntariamente.

O fundamento da atividade política do Conselho da Europa se baseia em que esta instituição é depositária da Convenção européia dos direitos do homem, cujo artigo dez trata daliberdadedeexpressão edalivre circulação de idéias, e da Conven ção Cultural Européia.

Depois da formulação, durante a primeira partedosanos 80, dediversasrecomendações sem poder executivo, o Consel ho da Europa sededicou, a partir daConferênciaMinisterial Européia sobre a Comunicação de Massas, realizada em Viena, em dezembro de 1986, à elaboração de uma Convenção européia sobre a televisão transfonteiriça, de âmbito similar à promulgada pela União Européia, equefoi adotado pelo Conselho de Ministros Europeus, em maio de 1989. Desde esta data, os diferentes estados membros do Consel ho da Europavêmretificandotal convenção através dos parlamentos nacionais.

A segunda iniciativa política significativa tomadapeloConsel hoemmatériaaudiovisual foi a criação, em 1989, de um Fundo Europeu de A juda à Co-produção e à D ifusão de O bras de Criação Cinematográficas e Audiovisual (EUROIMAGES), de acordo com o determinado pela Convenção Cultural Européia, estabelecido emEstrasburgo. I gual ao Programa MEDIA, o objetivo de EUROIMAGES é fomentar a co-produção e distribuição de programas por meio de ajudas financeiras parciais ou contribuindo com os custos de dublagem e subtitulação dos programas europeus.

De forma similar ao Programa MEDIA, EUROIMA GES abriu seus fundos aos países do Centro e Leste da Europa antes mesmo que façam parte da organização.

A elaboração paralela de políticas européias decomunicação por partedaUnião Européia e do Conselho da Europa gerou um duplo regimejurídicoeuropeu. Por umlado, aUnião criou diversas diretivas protecionistas inspiradas até o momento por considerações fundamentalmente de tipo econômico e industrial ( a livre circulação de serviços e a promoção das produções européias e sua difusão majoritariamente através das cotas exigidas na programação das Cadeias de televisão, ao menos em 50\%). Por outro, o Conselho da Europa criou convenções, inspiradas essencialmentepor considerações dedireito público ecultural ( livrecirculação de programas e promoção de obras culturais européias). Em geral, as políticas de ambas instituições são convergentes em numerosas disposições e contribuem para a cristal ização no espaço europeu de uma política audiovisual e coesa. Ambas instituições fomentam a política de cotas nas emissões detelevisão discutida pela associação de televisões privadas e o lobby publicitário europeu , entreoutros; aregulamentação dosconteúdos e do tempo publicitário ( de 15 a $20 \%$ do tempo de emissão em tel evisão); o direito de resposta; a proteção da infância e da juventude; a limitação e interrupção publicitária de emissões, etc.

\section{As iniciativas da União Européia de Radiodifusão (UER) e da Orga- nização Européia de Satélites de Comunicação (EUTELSAT)}

Junto às duas maiores instituições mencionadas na tomada das decisões políticas em comunicaçãonaEuropa,énecessárioassinalar 
o papel desenvolvido por outras duas organizações, aUER ea EUTELSAT, complementares das anteriores.

A UER foi fundada em 1950 e é o organismo internacional não-governamental queagrupa os serviços deradiodifusão da Europa, como objetivo decoordenar suasatividadesnoplano técnico, jurídico e de programação, em colaboração com diversos países eassociações de radiodifusão fora da Europa. Tem sede administrativa em Genebra e dispõe de um centro técnico emBruxelas. A través dequatro comissões - a de programa de rádio, a de programa detel evisão, a jurídica e a técnica , vem desenvolvendo suas atividades por mais de quarenta anos no espaço geográfico europeu. A mais conhecida dentre elas consiste no intercâmbio diário de notícias da atualidade entre seus membros. $O$ papel da UER naradiodifusão européiatemsido muito importante. A té datas recentes detinha, com exclusividade, os direitos sobre todas as grandes retransmissões esportivas e os grandes acontecimentos políticos e culturais europeus.

Em1987, nocontexto dasemergentespolíticas daUnião Européia edo Conselho da Europa, oConselho deA dministração daUER solicitou à Comissão de Programas de Televisão um estudo de viabilidade para o lançamento de uma cadeia européia deinformação contínua da atualidade. Este novo projeto é denominado Euronews e nasceu como uma amostra a mais da política européia de meios.

Dois anos depois, em 1989, o Conselho de Administração aprovou o Informe elaborado pelo Grupo Euronews, como uma ação de grande importância e com um grande significado na constituição do espaço audiovisual europeu. Posteriormente esta iniciativa se integrará no horizonte de objetivos esquematizados pelo Programa Eureka Audiovisual. Finalmente, dois anos mais tarde, recebe o respaldo do Parlamento Europeu e começa a funcionar em janeiro de 1993, nos arredores de Lyon, na França.
O canal de informação continuada Euronews é talvez, mesmo falido, uma das melhores iniciativas européias para fomentar uma autonomia audiovisual na atualidade informativa.

Está fundamentado nos recursos de informação explorados e que a televisão pública européia dispõe. Somenteuma mínima parte das noticias que se emitem nos diferentes espaços nacionais europeus consegue ser difundida no conjunto europeu (menos de $10 \%$ das notícias).

Como a UER gestiona todo o intercâmbio de notícias da Europa, é fácil e factível tecnologicamente desviar via satélite, todas as notíciasqueatelevisão européiadispõe, para um novo centro no qual se possa tratar de forma contínua, ou seja, vinte equatro horas por dia, em diferentes formatos e blocos.

Pensado e esquematizado como um canal público de direito privado com vocação e responsabilidades de serviço público, Euronews foi financiado nasuaprimeiraetapa por grandes empresas européias de radiodifusão (France Television, Radio-Television Espanhola, aRAI italianae, emmenor medida, pelas radiotelevisões públicas de Mônaco, Bélgica, Grécia, Finlândia, Portugal eSuíça) e suasinversõesiniciaisforam de25milhõesde ECUS.

Graças à nova tecnologia (arquivos automatizados, tratamento el etrônico da informação audiovisual, a pós- produção digital, adifusão multicanal deemissões, etc.), a informação se emite por via satélite, via hertziana e cabo a uma audiência de 10 milhões de lares, nos cinco grandes idiomas europeus e de forma sincrônica através decinco diferentes bandas de som (alemão, inglês, francês, italiano e espanhol) e já se está estudando a possibilidade de transmissões em russo eárabe.

A experiência da Euronews define como nenhumaoutraanovarealidadecomunicativa 
dosmacroespaçosecomoatecnologiapermite uma articulação flexível eenriquecedora das dinâmicas informativas e culturais entre os novos espaços locais, nacionais, regionais e mundiais.

Euronews, nos seus três anos de funcionamento, realizou umapolíticainformativa independenteedifundiu notíciasproduzidas de forma descentralizada pelos canais públicos de toda a Europa Ocidental, contribuindo de forma muito efetiva para a criação de uma nova visão sobre as identidadesinformativaseculturaiseuropéias(com mais de 7.300 horas de emissões no seu primeiro ano e 7.300 notícias emitidas, dentre asquais 40\%detemaseuropeus; 2.300 revistas; 43 retransmissões diretas, das quais 22 estavam dedicadas à política institucional européia). Como exemplo, em 1993, se trataramedifundiramnaEuropa 350notícias com tema espanhol. N unca, como por meio de Euronews, a visão do outro europeu esteve tão presente na sociedade européia.

Por último, é importante destacar outro ator menor da política européia. Está constituído pelo consórcio europeu EUTELSAT que integra as 26 administrações de Correios e Telecomunicações Européias, membros da ConferênciaEuropéia das Administrações de CorreioseTelecomunicações(CEPT). Eutel sat elabora, deacordo coma Comissão Européia, o planejamento do espaço para os satélites de telecomunicação. No ano passado lançou o satélite $H$ ot Bird, que será seguido este ano pelo $\mathrm{H}$ ot Bird II, para a difusão digital na Europa. O papel da Eutelsat vem sendo limitado pela emergência das empresas de satélites privados, como no caso do consórcio Astra, que vem liderando na Europa na emissão direta de sinais de televisão.

\section{Considerações finais}

As políticas públicas de comunicação na Europa apresentam uma contínua variação de problemáticas. Seguidamente vêm sendo criticadaspor abandonar osobjetivoscriativos e culturais frente à dinâmica do mercado ea uma estratégia errada que favorece a criação de grandes grupos multimídia de âmbito europeu, correndo o perigo de que se convertam em si mesmos, em poderes políticos reais que ameacem o pluralismo político eos próprios meios (como éo caso de Berlusconi, naltália, edeConde, naEspanha); e por criar quase tantos problemas quanto aparentemente solucionam (como no caso da liberalização audiovisual que favoreceu a tendência à compra de produtos norteamericanos e à comercialização do setor audiovisual europeu).

Por outro lado, se afirma que, para potencializar afrágil identidadedaculturaeuropéia se recorreu a uma simplificação do poder da cultura americana, o que por outra parte favoreceu a tomada de posições políticas protecionistas no espaço europeu.

A cima destas críticas reais, o que coloca de manifestoareflexãosobreaspolíticas públicas na Europa tem sido a interconexão dos desafios econômicos, industriais e culturais deste setor no meio da comunidade, a compreensão desta realidade passou a ser considerada prioritária na agenda política da sociedadeeuropéia. Osinteresseseconômicos do setor audiovisual são muito importantes. Um informe de um comissário europeu, em 1994, afirmava que o superávit norteamericano no setor audiovisual ascendia aos 3.400 milhões de dólares e que a demanda européia, devido ao incremento de canais, se duplicará antes do final do século. Estima-se em dois milhões os postos de trabalho que venham a ser criados pelo setor em uma década.

Ainda considerando todas as observações críticas pertinentes, as ações européias no audiovisual vêm se orientando muito acertadamente à busca de uma ação concentrada no triplo campo da tecnologia do audiovisual, na regulamentação e na harmonização do setor ena dinamização e estímulo 
do mercado da programação.

Sem dúvida, é difícil traduzir em iniciativas coerentes as posi ções políticas ambivalentes dos diferentes Estados queintegramaUnião. A sforçascentrífugaslibertadaspelo mercado resultamemocasiõesmais determinantesque os objetivos gerais que orientam a política de comunicação comunitária.

Duranteaúltimadécada, muitoseguidamente os acontecimentos vêm superando as expectativas e das diversas iniciativas comunitáriasemcomunicação estão surgindo os problemas da agenda política de amanhã: a potencialização da diversidade cultural européia como valor em si mesmo, a manutenção do pluralismo empresarial e informativo como garantia de aprofundamento da democracia, o equilíbrio entrea qualidade da produção e a concorrência de mercado; a procura de instituições independentes supranacionais que arbitrem os novos problemas surgidos pelo desenvolvimento dos meios de comunicação no espaço europeu ou a transformação da sociedade européia numa sociedade pósindustrial ou da informação .

\section{Referências}

BARZANTI, R. "La culture, paramètre vital de la 'societé européenne', in Coherence in diversity: the challenge for European television, European Institute for the Media, Machester. 1990.

BURGESS, A. "European culture: does it exist?", in European Broadcasting Union Review. VOL. XLI, no. 2, 1990:17-21.

COLLINS, R. Broadcasting and Visual Policy in the European M arket. John Libley. Londres. 1992.

KING, A.Culture, Globalization and the World-System. MacMillan. Londres. 1991.

MURCIANO, M. Estructura y dinámica de la comunicación internacional. Ed. Bosch. Barcelona. 1992.

MURCIANO, M. "Lo Global y lo local en las estructuras de comunicación internacional" in Revista Telos n. 37.

WATERS, M. Globalization. Ed. Rouletge. Londres. 1995.

Publicações da COMISSÃO DAS COMUNIDADES EUROPÉIAS:

Towards a European television policy. Bruxelas. 1984.

Television sin fronteras. Luxemburgo. 1984.

The media programme. Bruxelas. 1986.

La política de la comunidad europea para la industria audiovisual. Recopilación de textos legislativos y políticos. Luxemburgo. 1990.

La política audiovisual de la comunidad europea. Luxemburgo. 1992.

Opciones estratégicas para reforzar la industria de programas en el contexto de la Política Audiovisual de la Unión Europea. Luxemburgo. 1994.

Publicações do CONSELHO DA EUROPA:

European Convention on transfrontier television. Estrasburgo. 1989.

Council of Europe activities in the media field. Estrasburgo. 1991.

Publicação do OBSERVATÓRIO EUROPEU DEL AUDIOVISUAL:

Anuário estatístico. Consejo de Europa. Estrasburgo. 1995. 